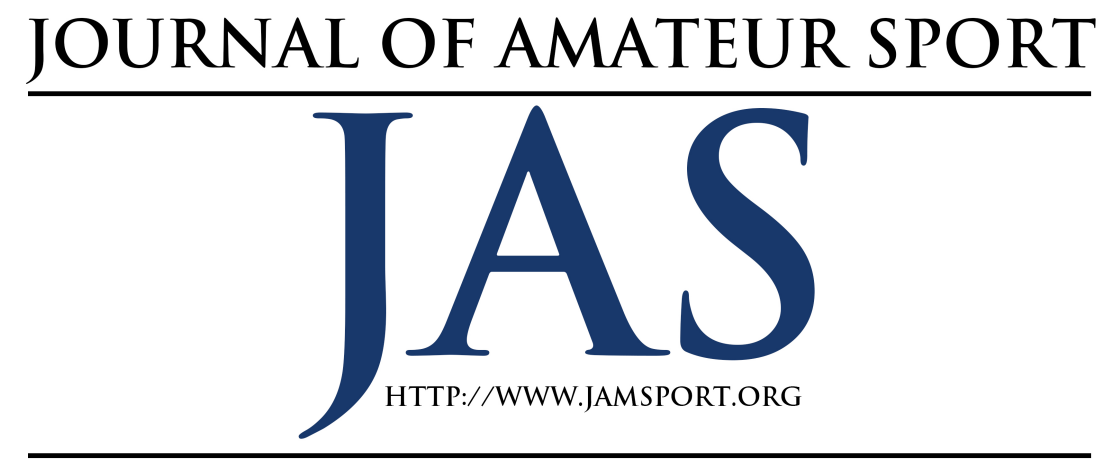

\title{
Economic View and Strategic Management View toward Understanding Outsourcing in Amateur Sport
}

\author{
Seungbum Lee \\ University of Akron
}

\begin{abstract}
Outsourcing as a strategic business decision has been a prevalent business practice in the sport industry, and as a result has been receiving increasing academic attention by scholars in sport management. In many cases, the academic attention has been focused on the multi-billion dollar hyper-commercialized sport industry, like professional and intercollegiate sport in the United States. However, outsourcing has infiltrated the world of amateur sport, for instance youth sports programs (YSP), as well. In spite of a growing use of outsourcing as a viable business strategy within a community based sport setting, efforts to understand outsourcing in amateur sport have so far gone unheeded in academia. Accordingly, this study examined outsourcing YSP by city-owned recreation centers (CORC). The motivation of outsourcing and the risk of outsourcing were analyzed using a multiple case study approach. The results of this study argue that combination of both economic and strategic management views are effective ways to understand outsourcing strategies in an amateur sport setting. The findings of this study provide both theoretical and practical implications. Furthermore, to contribute to the body of literature, the findings of this study are compared with previous sport management outsourcing literature to provide a comprehensive understanding of outsourcing.
\end{abstract}

$\mathrm{H}$

istorically, youth sport in America has been a popular form of activity (Coakley, 1979), and the youth sport participation for some sports is consistently increasing. Many major sports governing bodies have started to implement and run very attractive initiatives designed to promote youth sports participation across the country (e.g., Gray, 2015; Missal, 2015; Thomas, 2015). This trend by the major sports governing bodies presents a serious competition to many sport organizations like city-owned recreation centers (CORC), because they also sell 
youth sports programs. Also, CORC are facing huge challenges to be financially sustainable against major sports governing bodies that have better financial, physical, human, and informational resources than CORC. Additionally, many CORC have a relatively small number of full time employees and face a budgetary constraint as the financial support from cities is generally decreasing. As a result, many CORC are forced to adapt in a new and challenging market place. One of the notable changes is outsourcing YSP to independent contractors (Park and Recreation National Database Report, 2014). The National Alliance for Youth Sports (2012) also noticed recent trend addressing that "In recent years there has been a huge shift in youth sports with more and more municipalities outsourcing programs to independent volunteer-led organizations."

While a growing number of the cities are employing outsourcing strategies for their YSP, there has been no academic effort to understand outsourcing in terms of motivation, risks, and its mitigation strategies. Thus, given the paucity of investigation toward outsourcing YSP to better understand current amateur sport management, this study seeks to investigate why CORC outsource their YSP to a third party, and what outsourcing risks they have and how they mitigate those risks.

Such investigation is necessary for several reasons. First, outsourcing as a subject matter has been examined frequently in the context of sport management. However, a majority of published studies focused on a highly commercialized professional (Burden \& Li, 2009; Lee, 2010; Lee \& Lee, 2011) or an intercollegiate sport setting (Bouchert, 2010; Burden \& Li, 2005; 2003; Burden, Li, Masiu, \& Savini, 2006; Lee \& Walsh, 2011; Li \& Burden, 2004; 2002; Walker, Sartore, \& Taylor, 2009; Zullo, 2013a; 2013b), which can be characterized by commodification, commercialization, and marketization.

Scholars are belated to understand outsourcing in the context of YSP by CORC. It is believed that this study will contribute to the body of overall sport management literature in a unique way by focusing on the amateur sport context. Secondly, as Davis-Blake and Broschak (2009) argued, outsourcing is a complex, multi-dimensional, and heterogeneous practice depending on a wide range of variables affecting outsourcing success or failure. The outsourcing decision, as well as the operation, is much more complicated nowadays, so the traditional "make or buy decision" is gone. Academic efforts to understand outsourcing in areas where little exploration and theory exist will contribute to the body of sport management and outsourcing literature. Also, to contribute to the body of literature, the findings of this study are compared with previous sport management outsourcing literature to provide a comprehensive understanding of outsourcing. 


\section{Literature Review}

This study has three research questions that are developed by previous literature: What motivates the outsourcing of YSP?; What are the outsourcing risks to YSP?; And, what are the risk mitigation strategies used by YSP?

\section{Outsourcing Motivation/Risks}

Outsourcing as a strategic business decision has been used globally for many years across many different industries, and according to the Statista (2013), in 2013 the market size of the outsourced service was close to 83 billion dollars. Busi (2008) described outsourcing as a business strategy by an organization that contracts out one of its operations to an external and independent third party. For years, in academic literature such as information system, a vast amount of research from a number of different academic fields has been accumulated to better understand outsourcing.

Academic focus of outsourcing studies has become more diverse, and scholars have discussed different aspects of outsourcing (see Lacity, Solomon, Yan, \& Willcocks, 2011) such as transaction attributes (e.g., process complexity, risk, transaction costs, etc.), client firms (e.g., client size or age, prior firm performance, etc.), relational governance (communication, relationship quality, etc.), and outsourcing decisions (e.g., make or buy, multi-sourcing, etc.). Among these, outsourcing motivation and outsourcing risks are two of the most studied topics in literature (see Lacity et al., 2011). Regarding outsourcing motivation, several motivations have been identified such as cost reduction, focus on core activities, access to the resources/skills, performance improvement, innovation, and development of employees (see Lacity et al., 2011). There are two major outsourcing motivations: cost-driven and performancedriven outsourcing (Kremic, Tukel, \& Rom, 2006). Cost-driven outsourcing focuses on a cost reduction perspective. Minimization of indirect costs, such as fewer employees, is a primary example. Performance-driven outsourcing is an approach from a quality improvement point of view, and many organizations expect access to expertise/resources (e.g., Baldwing, Irani, \& Love 2001; Elmuti \& Kathawala, 2000; Kakabadse \& Kakabadse, 2000; Kumar \& Eickhoff, 2006; Mukherji \& Ramachandran, 2007) and expect professional development, like knowledge acquisition, through outsourcing (e.g., Barthélemy \& Quélin, 2006; Zach \& Singh, 2010). However, more often than not, a combination of these two motivations seems more common for outsourcing motivation.

Despite the benefits outsourcing brings to the organization (Fill \& Visser, 2000; Kremic et al., 2006), the outsourcing decision is not a panacea for all organizations as there are always risks associated with outsourcing. Previous outsourcing studies identified and discussed outsourcing risks and the necessary managerial actions to handle them (e.g., 
Aron, Clemons, \& Reddi, 2005; Bahli \& Rivard, 2003; Earl, 1996; Kremic et al., 2006; Willcocks, Lacity, \& Kern, 1999). Some of the risks are inherent in that those risks are present in any business, such as a hidden cost like a search for a service provider or contract negotiation with a service provider, a potential loss of control/competence, changing environment, conflict of interest and relationship issue. Also, outsourcing may lead to distrust toward the service provider and diminish employee's commitment (Bhagwati, Panagariya, \& Srinivasan, 2004). In addition, other types of risks related to various managerial risks include poor contract details, poor communication, and poor monitoring (see Kremic et al., 2006).

For a risk mitigation strategy, Key (1995) suggested a group of experts knowledgeable about not only outsourcing but its risks should manage a service provider's performance. In reality, outsourcing risks can occur in many different ways. One of the risks as a result of action by the service provider is called shrinking (Aron et al., 2005). It is the intentional under performance by the service provider while still claiming a full service fee, and it can stem from deliberate effort by individuals, untrained/inexperienced staff hiring, and under investment in resources by the service provider to get out of the existing contract or renew the existing contract (Aron et al., 2005; Earl, 1996). Shrinking will cause a significant and unexpected financial burden to the organization as they may have to manage the shrinking situations through a contract amendment, buyout, and so forth. Eventually, managerial risks incur hidden costs meaning that two different types of risks are very much affecting each other.

\section{Economic View and Strategic Management View}

There are several theoretical perspectives that discuss outsourcing and these theoretical perspectives have been proven effective to understand outsourcing. According to Cheon, Grover and Teng (1995), there are two major theoretical frameworks in outsourcing. The first one is an economic view based on transaction cost theory that emerged as a predominating theory to explain outsourcing. Economist Ronald Coase introduced the concept of transaction cost theory in the 1930s to discuss the cost, including time and effort incurred for any economic activity, in making any transaction in the market system (Coase, 1937). Then, it was developed further by Williamson in the 1970s. According to Williamson's view, any organization has two options for its economic activity; in-house performance or market mechanism like outsourcing. Either option has the cost involved such as production costs which consists of both direct and indirect cost to produce the good or service and other transaction costs needed for economic activity such as operational and contractual costs (Williamson, 1975; 1985). The main focus 
of the organization's decision is controlling and minimizing transaction costs through an external market mechanism if available rather than internally within the organization (Coase, 1937; Williamson, 1975; 1985). In the modern business world, it is always important to keep the transaction costs minimal, and there have been many business strategies to achieve it. Outsourcing has been proven to be an effective business strategy so much so that many outsourcing studies have been guided by transaction cost theory to explain outsourcing motivation (see Bolumole, Frankel, \& Naslund, 2007). Therefore, this framework explains that the organization tries to minimize the transaction costs and transfer the costs to the external third party should the costs arise (Williams, 1975; 1985).

While traditional outsourcing studies focused more on economics approaches, other aspects of organizational behavior started to be seriously examined (Silverman, 1999). The strategic management view utilizes a resource based theory to discuss how to formulate or implement outsourcing strategies for successful outsourcing outcomes (Cheon et al., 1995). The theory postulates that an organization is basically a set of resources and capabilities that are treated as strengths (Grant, 1991), and these resources and capabilities are important to create competitive advantages for any organization (Cheon et al., 1995). To discuss the resources, Grant (1992) categorized five different resources; some are tangible like financial and physical resources, and some are intangible such as human, technological, and reputation. The theory's underlying concept is that the organization can exploit the resources through agreement rather than extending the organizational boundaries (Silverman, 1999). With respect to outsourcing, any organizations lacking resources can choose options of purchases, strategic alliances, or outsourcing to make up for the resources and capabilities, and that is why this theory can be powerful to explain outsourcing (Grant, 1991). Similarly, any organizations performing below the expected or desired level, outsourcing can be a great business strategy to boost the effectiveness by taking advantage of the resources available externally (Teng, Cheon, \& Grover, 1995). Whereas these two theoretical frameworks are different in terms of unit of analysis (transaction vs. resources/capabilities) and criterion (minimizing costs vs. creating value), they complement each other (Espino-Rodriguez \& Padron-Robaina, 2006).

\section{Sport Management Outsourcing Study}

Outsourcing studies in the sport management field are not as prolific as general outsourcing literature, but the field has started to receive attention from the scholars. The topics include marketing management (e.g, Burden \& Li, 2005; Lee \& Walsh, 2011; Walker et al., 2009; Zullo, 2013a), sales management (e.g., Bouchert, 2010; Lee \& Pinheiro, 2014; Zulloa, 2013b), and concession management (Lee \& Lee, 
2011). Sport management literature shows that performance-driven outsourcing in terms of revenue maximization and the focus on core competencies are the dominant primary outsourcing motivations. Burden and $\mathrm{Li}$ (2005) also showed the case of one Division I athletic department that outsources its marketing operations so they can instead focus on other activities. Recently, Lee and Walsh's (2011) findings from a SWOT and Analytic Hierarchy Process (AHP) combined model demonstrated that a selected athletic department in a Division I program employed sport marketing outsourcing mainly because of performance-driven outsourcing motivation. They noted that revenue generation through sport marketing outsourcing is the most important for outsourcing decision making. Another influential outsourcing decision making factor they identified was the focus on core business. By outsourcing, the athletic department could and would focus more on some other activities such as fundraising, media relations, and facility operations. In their study, cost control was selected as an influential factor, but not as important as revenue generation or a focus on core activities. Lee and Lee (2011) also identified expertise that the service provider can bring is one of the major motivations of concession management outsourcing along with revenue generation and transfer risks. So while cost driven outsourcing was also identified as a motivation by some other studies (Lee \& Lee, 2011; Lee \& Pinheiro,
2014; Lee \& Walsh, 2011), it appears that performance-driven outsourcing is the dominating motivation in the context of sport management outsourcing.

Similarly, sport management studies identified and discussed outsourcing risks. Not only were inherent outsourcing risks discussed previously (Bouchert, 2010; Burden \& Li, 2005; Lee \& Lee, 2011; Lee \& Walsh, 2011), but managerial risks and how to mitigate them was also discussed in terms of communication (Walker et al., 2009) and performance monitoring (Lee \& Pinheiro, 2014; Lee \& Lee, 2011). Specifically, Walker et al. (2009) noted some potential downfalls to outsourced operations such as a degrading of service, loss of control by the client, service provider selection problem, and ineffective communication, and also argued that potentially, these risks may create an 'us against them' dichotomy. Overall, outsourcing risks in sport management studies are very consistent with general outsourcing studies, meaning that risks existing in outsourcing are quite universal.

Regarding the theoretical frameworks, strategic view appears to be a dominating theoretical perspective due to the fact that a majority of previous studies viewed outsourcing as a strategic opportunity to deliberately gain resources from the service providers such as financial (Lee \& Walsh, 2011), physical (Lee \& Lee, 2011), human (Burden \& Li, 2005; Lee \& Lee, 2011; Lee \& Pinheiro, 2014; Lee \& Walsh, 2011; Walker et al., 2009), and technological 
resources (Lee \& Lee, 2011). Thus, outsourcing as a business strategy can be an impactful business decision as it can provide a strategic opportunity for the sport organization to obtain competitive advantages through resources the service provider possesses. Economic view focuses on cost control for the organization, and some studies in sport management outsourcing addressed and/ or investigated this view (Lee \& Lee, 2011; Lee \& Pinheiro, 2014; Lee \& Walsh, 2011). Although these studies addressed the economic view, all of these studies combined both the economic and strategic view to better understand outsourcing in the context of sport. Thus, while these two views may have different approaches to describe, analyze, and understand complex nature of outsourcing function, sport management outsourcing studies do complement each other's view point, which is very consistent with general findings of outsourcing studies (EspinoRodriguez \& Padron-Robaina, 2006).

\section{Outsourcing Youth Sports Programs (YSP)}

Understanding outsourcing in amateur sport has been somewhat overlooked.

Therefore, there is not enough academic knowledge regarding why CORC outsource YSP and how CORC manage outsourcing. Traditionally, many outsourcing cases in sport focused on professional or intercollegiate sport. A couple of explanations why the focus on professional and collegiate sports outsourcing has been dominating in literature instead of amateur sports might be possible. One, it is assumed that these highly commercialized sports receive mass media attention on a daily basis, so scholars started to look at outsourcing as a subject matter in both a professional or collegiate sport context (Coakley, 1979). Another possible explanation might be the fact that amateur sport has not been really operated as a business, unlike professional or collegiate sport. Outsourcing is viewed as a strategic business decision for an organization (Busi, 2008), and, traditionally, amateur sport has not been operated in such a way because it probably didn't need a business strategy for its operation. Yet, recently, some studies from outside of the United States have discussed amateur sport examples that outsource physical education or coaching classes to the third party (Aoyagi et al., 2014; Whipp et al., 2011; Williams et al., 2011). Williams et al. (2011) found that many schools in Australia outsource sport and physical educational work such as outdoor adventure and extra-curricular activities. This study found that outsourcing motivation includes access to expertise/resources and teacher professional development. That is to say, the schools outsource to get access to specialized skills (i.e., how to run sports programs, etc.) and resources (i.e., facilities, information, etc.) which the school can not access without hiring and working with the service provider. Whipp et al. (2011) found that outsourcing physical education to the 
specialized service providers allows teachers to enhance confidence and skills of teaching physical education effectively. As a result, teachers from the schools also receive educational opportunities for their professional development by associating with the service provider.

The primary outsourcing motivation in the case of physical education or coaching appears to be performance-driven outsourcing. This is not inconsistent from other previous sport management outsourcing studies that support mainly performance-driven outsourcing.

\section{Method}

To understand the contemporary phenomenon of outsourcing YSP by the CORC, a multiple case study approach was used for this study (Woodside \& Wilson, 2002). Multiple bounded systems (cases) are explored through research questions of how and why in the context of contemporary and real life contexts (Yin, 2003). To be specific, the interview questions are modified and developed based on Rottman and Lacity (2008) and Mclvor (2009)'s interview questions to understand 'why' and 'how' questions with respect to outsourcing decision, outsourcing risks, and its mitigation strategies.

The CORC in this study means a cityowned recreation center managed by a park and recreation department that promotes health and well-being of the residents through a wide range of programs for people of all ages. The CORC used in this case study are all from one state in the northeast United Sates. This study examined three different CORC that are outsourcing their YSP. For confidentiality purposes, these three CORC will be referred to as Case 1, Case 2, and Case 3. There are two reasons for selecting these particular CORC. Firstly, all CORC have been using an outsourcing model for years for their YSP operations, which will provide ample information to understand outsourcing motivation, risks, and its mitigation. Secondly, the researcher has relationships with the CORC, and it is believed that the relationship would provide quality of data through the interview (Eisenhardt, 1989).

To collect the data, an in-depth interview, follow up email conversation, and secondary data (e.g. webpages, brochures, online documents) were used. To solicit rich data to answer the research questions of this study, interviews with the manager in charge of YSPs were conducted. Each interview lasted between 30 and 45 mintues. A semistructured interview with the personnel from three CORC highly involved in outsourcing YSP, as well as number of other resources, such as documents, minutes, and newspaper articles pertaining to outsourcing YSP, were used for data triangulation (Stake, 1995; Yin, 1981).

\section{Case 1 Description}

Case 1 is a 100,000 square-foot health, fitness, wellness and recreation center that serves the residents of the community. It offers a variety of sports programs, leagues, 
and fitness classes for all ages. The recreation center was opened 11 years ago, but they have been outsourcing YSP, such as basketball, soccer, flag football, tennis, and others depending on seasonal demands using multiple service providers for at least 5-6 years. Revenue sharing is $75 \%$ to the service provider and $25 \%$ to Case 1 . There are only 3 full time employees, including one administrative assistant, who are all city employees. Furthermore, they have more than 80 part-time employees who can only work 20 hours maximum per week. As for a selection of the service provider, there is no official request for proposal (RFP) and bidding process. Historically, a potential service providers proposed an idea informally. For example, ideas such as, "Do you have karate classes?" or "Do you have tennis classes?" were asked. If the Assistant Recreation Facility Manager in Case 1 is interested, an official meeting will be scheduled to discuss the possibility of outsourcing internally. Given that Case 1 is family-oriented in its daily operations and examines if there is a fit between the two organizations. The Assistant Recreation Facility Manager said, "They need to understand what our mission is, what our vision is, and how we conduct the business...Don't want to misrepresent who we are because the (YSP) programs still represent us. We are city employees so we represent the city." Once all three employees agreed that certain service providers fit, the Director of the Recreation Center presented the outsourcing plans to the governing board, which included the mayor, city finance director, and legal expert of the city. After this presentation, the mayor presented the findings to the city council. The YSP outsourcing model was viewed as a viable business option to effectively and efficiently run the CORC, because the city clearly understood how much the CORC was understaffed. Once the service provider was formally selected and contracted, the service provider would do a background check, hire the instructors, advertise YSP, and pay the instructors.

\section{Case 2 Description}

Case 2 provided a diverse array of programs that promote fitness, health, enjoyment, and education. Case 2 has experienced a huge managerial challenge because of an economic slowdown. Five years ago, the city stated it would discontinue financial support to the Case 2, and it has forced Case 2 to develop a different organizational structure and financial plan. While there were no clear reasons announced publicly as to why the city cut the budget for Case 2 , it is quite safe to assume that it was to lessen the financial burden of the city's general fund. Specifically, utility costs increases ranged between 50 and 100 percent, and the CORC was in the red for years, which forced the city to reconsider its financial support to the CORC. Besides, a financial investment in the CORC and its YSP is perceived as less of a priority by the city. Generally, it is not surprising to see the local government cut 
spending for the recreation center and its programs and transfer its spending to other local services such as police or fire department (Potkewitz, 2008; Sword, 2009). Therefore, it underwent a huge downsizing, reducing the number of full time employees from 20 to only two for the entire department, which forced them to outsource a lot of their programs including YSP. Due to no financial support from the city, Case 2 had to generate its own sources of revenues and, mainly, it heavily relied on program/membership income $(90 \%)$. The CORC had a record-breaking profit year mainly stemming from increased program/ membership fees in 2014, sponsorship with a regional hospital and other sources of revenue such as donation, rentals, vending machines, and leases (10\%). Since the sponsorship deal had just expired, it could mean less sponsorship revenue for Case 2 . Case 2 had a sponsorship with a local hospital back in 2009 for three years and had another three year sponsorship with another regional hospital. Case 2 is now seeking another three year sponsorship. Case 2 outsources a lot compared to other CORC as $70 \%$ of their programs are currently outsourced to multi service providers.

Case 2 has two different approaches, both formal and informal, for their service provider recruitment and selection. After opening up the RFP locally, about five selected prospective bidders were invited for presentations. Case 2 selected the service provider that could "minimize the production costs and benefit the community by serving its residents." For instance, Case 2 selected the service provider that said "we will also maintain the field" for the YSP. Case 2 was able to significantly reduce production costs.

\section{Case 3 Description}

Opened in 2002, Case 3 has an 110,000 square foot facility that provides recreational spaces. Case 3 CORC, a joint project between the city and city schools, has 6 full time employees. Although they receive a small financial subsidy from the city, the recreation department is expected to be self-financing so they have to generate enough revenue for their operation. Case 3 contracted some of its YSP to only two service providers, both out-of-town companies, which is a major difference from the previous two cases. Case 3 is working very closely with the Rec Advisory Board that is responsible for working collaboratively on the operational and managerial matters in accordance with the Operating Agreement between the organization, city, and city schools. Also the Recreation Advisory Committee comprised of six members (two city representatives, two city school representatives, one president at large, and two members at large) works closely with the Case 3 as well. So many programs including YSP are operated internally. Case 3 has an application form available anytime for the prospective service providers. If there is a need for certain YSP, and no in-house 
option is available, the employees make a selection of who will run a specific YSP based on a number of decision making criteria. A revenue sharing model, the service provider's previous experience, the feeling of trustworthiness toward the potential service provider are regularly used decision making criteria.

\section{Results}

\section{Outsourcing Motivation and Risk}

Case 1 revealed that the major motivation for outsourcing YSP was to bring expertise and, at the same time, cost minimization. A lack of full time employees forced them to heavily rely on external manpower. Such ideas were represented when it was said, "the city pretty much understands the way our office works... We can't really offer any additional programing with our own staff." Also the experienced service providers are in charge of hiring the instructors for each program and running the YSP. In doing so, Case 1 does not have to spend its time and resources on hiring full time city employees and worrying about their pensions and health plans. Both costdriven and performance-driven outsourcing motivation were identified in the Case 1 situation. In Case 2, the main outsourcing drive is also the combination of two. By hiring part-timer employees instead of fulltime employees and by hiring the external service providers that can bring the expertise in the area of YSP, they can "take pressure off by outsourcing." The interview showed that Case 2 does not outsource revenue-generating programs (e.g. summer camps). Instead, they handle those programs internally to keep the revenue, yet they outsource relatively unimportant YSPs. Although outsourcing is not a main business model for YSP for Case 3, still Case 3 outsources some YSP because of the expertise that the service provider can bring which Case 3 does not have, and also cost reduction.

Outsourcing motivation between general business and sport organizations are not inconsistent in that mainly cost driven outsourcing and performance driven outsourcing are the main motivation. According to the interviewees, outsourcing motivation is focused on financial considerations. According to previous outsourcing studies, many small and medium-sized companies in America outsource their operations partly because of the cost saving (Coward, 2003), and, consistently, this case study supports that small organizations in sport also outsource for a cost saving reason. As Table 1 shows, the number of the full time city employees is extremely small to serve the city, so the size of the CORCs forced them to control the cost and take advantage of the resource available outside of the organization.

Theoretically, this result can be understood from both an economic view (transaction cost theory) and strategic management view (resource based theory), and it appears that there is no one dominating theoretical framework to 
describe outsourcing motivation; rather, it is integrated with more than one theory.

To be specific, all three cases expect both production cost and transaction cost reduction by exploiting mainly human resources from the service providers externally available in the market place through the contracts.

Case 1 shared a couple of different previous situations where outsourcing risks of loss of control occurred, but noted that these are quite minor risks for them as it did happen very rarely. Case 1 said that "we have problem solving and decision making power". Case 2 had not experienced outsourcing risks. Case 2 said, "they follow our rules" and added that they have built and maintained a great relationship with the multiple service providers based on mutual respect and trust. This helped them to avoid any potential outsourcing risks. Case 3 also did not really face any outsourcing risks as they created and maintained very good working relationships with the service providers. Also Case 3 added that their contract details helped them avoid getting involved with any outsourcing risks. Overall, all three cases did not experience any major outsourcing risks, which is a very interesting result in that it is different from previous sport management outsourcing studies that identified a set of outsourcing risks (Bouchert, 2010; Burden \& Li, 2005; Lee \& Lee, 2011; Lee \& Pinheiro, 2014; Lee $\&$ Walsh, 2011; Walker et al., 2009).

To summarize, the result of this study showed that the motivation of YSP outsourcing by CORC is explained by the combination of both economic and strategic management view; as opposed to one single dominating view point. As for transaction cost theory, this study found cost control is the primary motivation for CORC outsourcing YSP. Specifically, by collaborating with the service provider specialized in YSP, CORC can minimize the cost of YSP operations. Dyer and Singh (1998) noted that the use of combined resources across organizations would create competitive advantages. To create competitive advantages, CORC employ outsourcing strategy for YSP operations by purchasing service provider's expertise in cost effective way. Accordingly, it shows how two theoretical views are interconnected with each other.

As for outsourcing risks, unlike previous sport management outsourcing studies, this study does not show a huge concern of outsourcing risks. The interviews showed that outsourcing risks, such as lack of communication, conflict of interest, or loss of control, were quite minimal to be a serious managerial concern. Internally, CORC has outsourcing risk mitigation plan in place as a form of a detailed contract. Externally, the size of two organizations (CORC and service provider) being so small help them to manage any potential risks through effective communication and trust developed for years through mutual respect between two. 


\section{Discussion}

All the CORC in this study are facing financial challenges as the tax support from the city is decreasing. More than likely this trend, due to an economic slowdown, affected many CORC throughout the country. Like Case 3 expressed during the interview, the fact that a service oriented nonprofit community organization is "running a (CORC) business and making money to run the program (YSP)" has become a major financial and managerial challenge. This challenging situation forces the CORC to create ways to better manage their programs including YSP, and the use of outsourcing has become a widespread strategy.

As for outsourcing risks, this case study found a mixed result. Case 1 showed a low level of concern over such risks based on previous incidents whereas Case 2 and 3 did not experience such issues. However, all three cases were aware of the importance of outsourcing risks, so working with the service providers to create mutual benefits is taken seriously (Narasimhan \& Das, 2001). It has to be noted that few outsourcing risks examples (e.g., loss of control, conflict of interest, etc.) were presented during the interview. Yet, it was not clear from their answers whether or not they were aware of other types of outsourcing risks like hidden or unexpected costs associated with outsourcing such as contract changes, monitoring, bidding process, and others (Aron et al., 2005; Bahli \& Rivard, 2003; Earl, 1996; Kremic et al., 2006; Willcocks et al., 1999). Knowledge about hidden costs is practically important in that the

organization should not be misguided about the benefits of outsourcing as there might be hidden costs involved for successful outsourcing and, moreover, knowledge about hidden costs allowed the organization to develop an outsourcing risks mitigation mechanism.

One effective outsourcing mechanism that can prevent outsourcing risks from occurring is a dual sourcing strategy (Bahli \& Rivard, 2003; Kern, Wilcocks, \& Heck, 2002). Dual sourcing is one of the risk mitigation mechanisms through a multivendor strategy. The multi-vendors strategy creates a situation where there is a competitive environment between the service providers, and it motivates the service providers to outperform each other. While it may appear these cases use the dual sourcing strategies with multiple service providers, none of the people interviewed addressed or implied a dual sourcing strategy as an outsourcing mitigation mechanism. This implies that the CORC had a dual sourcing model for cost minimization by looking for better fits to find the service providers. Interestingly, given no reported serious concern over potential outsourcing risks, it appears to be working because it is assumed that the service providers are motivated to perform well and earn repeated service contracts with the CORC. Given that many service providers for this case study come from small local organizations, losing the client 
will hurt their business significantly so they always have a performance level they have to satisfy. Previous outsourcing studies found that the size of the service provider does not affect the performance (Lacity et al., 2011; Nadkarni \& Herrmann, 2010). This study supports that notion because even though the service providers are understaffed, CORC are still very satisfied with the performance by the service providers. So the results of this study support previous studies about the relationship between the size of the service provider and its performance. While it may work as a mitigation mechanism, it could work better if the CORC know how to strategically utilize the benefits of the dual sourcing strategy. Such benefits could include how to create friendly competition among the service providers or how to promote collaborative working relationships with all stakeholders involved in outsourcing.

Another potential mitigation plan that seems to be working very well is the contract details. Previous studies found that there is a positive relationship between outsourcing contract details and outsourcing success (Niranjan, Saxena, Bharadwaj, 2007; Wullenweber, Beimborn, Weitzel, \& Konig, 2008). Although all of the cases are extremely understaffed, they present great examples of taking care of contract details which is possible because they are working for the city. According to the interviews, it seems that contract completeness, such as clauses that address and clarify specificity of outsourcing details, is covered. Contract details are important for CORC in that it can act as a quality control mechanism such as performance monitoring and problem solving procedures. Contract details are vital for any potential disputes or litigation because the contract details act as a managerial guideline for both parties. Overall, as Table 2 shows, all cases reported that they are highly satisfied with their outsourcing mitigation mechanism.

\section{Comparisons to Previous Sport Management Outsourcing Research}

Findings of this multiple case study can be compared with the findings from previous outsourcing studies in sport management. Since previous sport management outsourcing research focused on only highly commercialized professional or intercollegiate sport, the investigation of amateur sport focusing on YSP provided by the CORC and its outsourcing strategies will provide better understanding about outsourcing.

There are several outsourcing motivations identified in previous sport management outsourcing research: revenue generation, quality improvement, cost reduction, access to the expertise, a focus on core activities, risk mitigation/sharing, mimic behavior and, many times, a combination of these factors (e.g., Burden \& Li, 2005; 2009; Lee \& Walsh, 2011).

Many cases, however, of professional or intercollegiate sport seek primarily revenue maximization or generation through 
outsourcing; accordingly, the result of this study is somewhat different in that revenue generation is not the primary outsourcing motivation. All cases briefly discussed the assignment of generating revenue for business, but it is not perceived as a high pressure for the cases. Case 3 reported that, "I am not sure outsourcing will bring more revenues to us", which was implied by the other cases. So, it is quite safe to argue that amateur sport organizations providing YSP are still not a highly business-oriented sport entity in our society. Similarly, Case 2 reported that to be self-supporting without a tax levy or appropriations from the general fund is important but not revenue generating. Case 2 ended last fiscal year with a record-breaking profit but it will fund several repairs and improvements within the CORC. Therefore, although there is an indication of the need to make money in order to be a self-financing organization, it appears that the operation of the YSP through the CORC is based on fulfilling its mission by serving the city residents, rather than revenue maximization or generation to which professional or intercollegiate sports are dedicated.

While previous sport management outsourcing studies addressed outsourcing risks (Bouchert, 2010; Burden \& Li, 2005; Lee \& Lee, 2011; Lee \& Pinheiro, 2014; Lee \& Walsh, 2011; Walker et al., 2009), all three cases reported no major outsourcing risks. It is not clear if the cases did not really experience outsourcing risks or that risks were so minimal that they were not addressed. Yet it appears that it is not a major managerial or financial issue for the cases, which is different from previous sport management outsourcing studies. One possible answer is that typically the CORC prefer to hire either local or regional service providers with which they have built relationships over the years. This makes both parties handle the risks in a very effective and efficient way before it becomes a serious issue. Another answer might be the fact that, as addressed earlier, these service providers are fairly small organizations, so it is safe to assume that they want to avoid any potential issues by maintaining good business and professional relationships with the CORC. It might be an ideal situation for all the cases as they can avoid outsourcing risks such as relational governance, financial incongruence, and conflict of interest with the service providers.

Unlike previous sport management outsourcing studies that focus on a primarily strategic view to address revenue generation, improved quality, or focus on other activities through outsourcing, this case study can be understood better through the combination of both an economic and strategic management view as opposed to one dominating viewpoint. All cases in this study addressed the importance of minimizing production and transaction costs (economic view) as well as creating resources or developing capabilities (strategic management view). In other words, it may be insufficient or 
inappropriate to have only one view to fully grasp the nature of outsourcing in the amateur sport context.

\section{Practical Implications}

Based on the results of this study, there are several practical implications for the manager from the CORC in terms of how to mitigate risks. If CORC decide to outsource, the manager should be knowledgeable about and familiar with outsourcing, outsourcing relationships, and most importantly, risks involved to better understand overall outsourcing implementation. Trust between service provider and client as a key influential factor for successful outsourcing, has been proven in previous research (Gainey \& Klass, 2003; Oza, Hall, Rainer, \& Grey, 2006; Sabherwal, 1999). Knowledge as well as efforts to create and promote good trust-based relationships between employees, full or part-timers, from the CORCs and service providers will serve as a foundation of successful outsourcing for the CORCs. To be specific, more formal collaborative projects between two organizations and further informal relationships, such as golf outings or retreats for both organizations, will create more trust building opportunities. In fact, this practical implication is relatively easier to implement as both the CORC and service providers are quite small in terms of staff. As a result, the CORC might be able to reduce costs for monitoring service provider performance which eventually will minimize the risks of creating or increasing unexpected or hidden costs (Gainey \& Klass, 2003; Sabherwal, 1999). Also, without actual monitoring by the CORC, outsourcing risks, such as shrinking, can be avoided in many cases because trust-based relationships will act as an outsourcing risk mitigation mechanism.

Similar to trust building, effective communication is very crucial.

Communication has been such an important concept for successful outsourcing as noted by previous outsourcing literature (e.g., Chen \& Paulraj, 2004; Gainey \& Klaas, 2003; Sen \& Shiel, 2006). Sen and Shiel (2006) addressed the importance of communication between the leaders from both the service provider and client to better understand each other. Chen and Paulraj (2004) noted the importance of not only the intra-organizational communication but also inter-organizational communication because all parties involved in outsourcing should communicate effectively and efficiently. Walker et al. (2009) specifically investigated a communication-commitment relationship with regards to sport marketing outsourcing within the athletic departments in the United States. They found that while sport marketing employees perceive sport marketing outsourcing as critical, they also experienced dissatisfaction with the frequency, level, and direction of communication, which could potentially hurt the business partnership between the organizations involved in outsourcing (Burden \& Li, 2002; Walker et al., 2009). 
So as a manager of the CORC, it is quite important to have good communication skills with the multiple stakeholders. Unlike many service providers working for the athletic departments, all the service providers for this study are very small in terms of staff, and it makes the managers from the CORC communicate more effectively and efficiently as they may have less frequencies, levels, and directions to go through for communication. Practically, trust and communication will be important from the economic view because these two will significantly reduce transaction costs by the CORC like service provider search cost, service provider selection cost, bargaining cost, enforcement cost, and cost of coordinating work with the service provider (Williamson 1975; 1980).

Another recommended way of monitoring is better management of dual sourcing (Bahli \& Rivard, 2003). In spite of the benefits of the dual sourcing strategy from the CORC standpoint, it may be understood somewhat differently by the service providers. The service providers may think their business is always in danger of losing the client, and may have concerns about how their performance is perceived by the CORC. A multiple service providers structure may create a competitive relationship between them. Therefore, the CORC may need to inform and discuss the nature of dual sourcing with the service providers so that no service providers misunderstand the true mission of the dual sourcing strategy. Hence, the CORC can create the best outcomes out of a dual sourcing strategy. For instance, the CORC may employ dual sourcing strategy for YSP for soccer. Soccer programs for very young players may go to one service provider that specializes in youth skill development, and the program for older players goes to another service provider that may have more expertise in that age level with more advanced skills development.

Lastly, while outsourcing YSP is perceived satisfactorily by the CORC according to the interviews, there have been no comments about how the service provider's performance is measured for internal review. It seems, however, that the CORC simply assume outsourcing is working. Having formally structured performance measure metrics will be helpful for an outsourcing failure prevention purpose.

\section{Limitations and Future Research}

Like other studies, this one has its limitations. Essentially, this study focused on youth sport to understand amateur sport and its use of outsourcing by centering on CORC. The results of this study may be different from other amateur sport, like that of high school or other types of community based adult sports leagues. Future research on such other types of amateur sport could enhance the understanding of outsourcing in amateur sport. In addition, the three CORC used in this study are all from the same northeastern state, so further examination of CORC from different states 
with different sizes of population, levels of household income, and a city budget could help to significantly contribute to the body of literature by providing a more comprehensive study of current outsourcing in amateur sport.

\section{Conclusion}

This case study examined YSP and the contemporary business nature of amateur sport by focusing on outsourcing as a business strategy. Whereas this case study is exploratory, its intent is to create academic attention and promote further examination from a field that has been receiving little to no academic attention. This study provided academic and practical implications for sport managers from the CORC who should be knowledgeable about contemporary phenomenon and future trend as to outsourcing. Certainly outsourcing in amateur sport as a serious academic area of study needs to be researched further, and this study provided initial steps for that journey. 


\section{References}

Aron, R., Clemons, E., \& Reddi, S. (2005). Just right outsourcing: Understanding and managing risk. Journal of Management Information Systems, 22(2), 37-55.

Aoyagi, K., Ishii, K., Shibata, A., Arai, H., \& Oka, K. (2014). How to outsource coaching in school-based extracurricular sports activities: Evaluating perceptions of external coaches. International Journal of Education, 6(3), 101-118.

Bahli, B., \& Rivard, S. (2003). The information technology outsourcing risk: A transaction cost and agency theory-based perspective. Journal of Information Technology, 18(3), 211-221. Baldwing, L., Irani, Z., \& Love, P. (2001). Outsourcing information systems: Drawing lessons from a banking case study. European Journal of Information Systems, 10(1), 15-24

Barthélemy, J., \& Quélin, B. (2006). Complexity of outsourcing contracts and ex post transaction costs: an empirical investigation. Journal of Management Studies, 43(8), 1775-1797.

Bhagwati, J., Panagariya, A., \& Srinivasan, T. (2004). The muddles over outsourcing. The Journal of Economic Perspectives, 18(4), 93-114.

Bolumole, Y., Frankel, R., \& Naslund, D. (2007). Developing a theoretical framework for logistics outsourcing. Transportation Journal, 46(2), 35-54.
Bouchert, A. (2010). Linking outsourcing of sponsorships to athletic department strategy: An agency perspective. Journal of Sponsorship, 3(3), 277-283.

Burden, W., \& Li, M. (2009). Minor League Baseball: Exploring the growing interest in outsourced sport marketing. Sport Marketing Quarterly, 18(3), 139-149.

Burden, W., Li, M., Masiu, A., \& Savini, C. (2006). Outsourcing intercollegiate sport marketing operations: An essay on media rights holders' strategic partnership decisions. International Journal of Sport Management, 7(4), 474490.

Burden, W., \& Li, M. (2003). Differentiation of NCAA division I athletic departments in outsourcing of sport marketing operations: a discriminate analysis of financial-related institutional variables. International Sports Journal, 7(2), 74-81.

Burden, W., \& Li, M. (2005). Circumstantial factors and institutions' outsourcing decisions on marketing operations. Sport Marketing Quarterly, 14(2), 125131.

Busi, M. (2008). Editorial. Strategic Outsourcing: An International Journal, 1(1), 5-11.

Chen, I., \& Paulraj, A. (2004).

Understanding supply chain management: critical research and a theoretical framework. International Journal of Production Research, 42(1), 131-163. 
Cheon, M., Grover, V., \& Teng, J. (1995).

Theoretical perspectives on the outsourcing of information systems. Journal of Information Technology, 10(4), 209-220.

Coakley, J. (1979). Participation trends in physical activity and sport:

Implications for the sociology of sport. Review of Sport and Leisure, 4, 3147.

Coase, R. (1937). The nature of the firm. Economica, 4(16), 386-405.

Coward, C. (2003). Looking beyond India: Factors that shape the global outsourcing decisions of small and medium sized companies in America. The Electronic Journal on Information Systems in Developing Countries, 13(11), $1-12$.

Davis-Blake, A., \& Broschak, J. (2009). Outsourcing and the changing nature of work. Annual Review of Sociology, 35, 321-340.

Dyer, J., \& Singh, H. (1998). The relational view: cooperative strategy and sources of interorganizational competitive advantage. Academy of Management Review, 23(4), 660-679.

Earl, M. (1996). The risks of outsourcing IT. Sloan Management Review, 37(3), 2632.

Eisenhardt, K. (1989). Building theories from case study research. Academy of Management Review, 14(4), 532-550.

Elmuti, D., \& Kathawala, Y. (2000). The effects of global outsourcing strategies on participants' attitudes and organizational effectiveness. International Journal of Manpower, 21(2), 112-128.

Espino-Rodriguez, T., \& Padron-Robaina, V. (2006). A review of outsourcing from the resource-based view of the firm. International Journal of Management Reviews, 8(1), 49-70.

Fill, C., \& Visser, E. (2000). The outsourcing dilemma: a composite approach to the make or buy decision. Management Decision, 38(1), 43-50.

Gainey, T., \& Klaas, B. (2003). The outsourcing of training and development: Factors impacting client satisfaction. Journal of Management, 29(2), 207-229. Grant, R. (1992). Contemporary Strategy Analysis: Concepts, Techniques, Applications. Cambridge, MA: Basil Blackwell.

Grant, R. (1991). The resource-based theory of competitive advantage: implications for strategy formulation. California Management Review, 33, 114135.

Gray, R. (2015). Golf programs see surge as industry counters staid image. Sports Business Journal, 18(17), 18.

Kakabadse, N., \& Kakabadse, A. (2000). Critical review-outsourcing: A paradigm shift. Journal of Management Development, 19(8), 670-728.

Kern, T., Wilcocks, L., \& Heck, E. (2002). The winner's curse in IT outsourcing: strategies for avoiding relational 
trauma. California Management Review, 44(2), 27-69.

Key, R. (1995). Outsourcing: how to contract with third party vendors. ABA Bank Compliance, 16(4), 5-12.

Kremic, T., Tukel, O., \& Rom, W. (2006). Outsourcing decision support: A survey of benefits, risks, and decision factors. Supply Chain Management: An International Journal, 11(6), 467-482.

Kumar, S., \& Eickhoff, J. (2006).

Outsourcing: When and how should it be done?. Information Knowledge Systems Management, 5(4), 235-259.

Lacity, M., Solomon, S., Yan, A., \&

Willcocks, L. (2011). Business

process outsourcing studies: a critical review and research directions. Journal of Information Technology, 26(4), 221258.

Lee, S. (2010). Global outsourcing: A different approach to an understanding of sport labor migration. Global Business Review, 11(2), 153-165.

Lee, S., \& Pinheiro, V. (2014). Outsourcing sport sponsorship sales to sport management classes: Benefits and risks. Journal of Brand Strategy, 3(2), 185-193.

Lee, S., \& Lee, S. (2011). How much do we know about concession? What outsourcing can explain about concession management. International Journal of Developmental Sport Management, 1(1), 1-18.
Lee, S., \& Walsh, P. (2011). SWOT \& AHP hybrid model for sport marketing outsourcing using a case of intercollegiate sport, Sport Management Review, 14(4), 361-369.

Li, M., \& Burden, W. (2004). Institutional control, perceived product attractiveness, and other related variables in affecting athletic administrations' outsourcing decisions. International Journal of Sport Management, 5(4), 1-11.

Li, M., \& Burden, W. (2002). Outsourcing sport marketing operations by NCAA Division I athletic programs: An exploratory study. Sport Marketing Quarterly, 11(4), 226-232.

Missal, J. (2015). Lacrosse uses personal touch to continue its steep growth curve. Sports Business Journal, 18(17), 18.

Mukherji, S., \& Ramachandran, J. (2007). Outsourcing: Practice and searching of a Theory. IIMB Management Review, 19(2), 103-110.

Nadkarni, S., \& Herrmann, P. (2010). CEO personality, strategic flexibility, and firm performance: The case of Indian business process outsourcing industry. Academy Management Journal, 53(5), 1050-1073.

Narasimhan, R., \& Das, A. (2001). The impact of purchasing integration and practices on manufacturing performance. Journal of Operations Management, 19(5), 593-605. 
National Alliance for Youth Sports. (2012). Resources for recreation departments and public officials. Retrieved from http://www.nays.org/municipalities/ index.cfm

Niranjan, T., Saxena, K., Bharadwaj, S. (2007). Process-oriented taxonomy of BPOs: An exploratory study. Business Process Management Journal, 13(4), 588606.

Park and Recreation National Database Report (2014). Retrieved from http://www.nrpa.org/uploadedFiles /PageBuilder_Proragis/Content/co mmon_elelments/NationalDatabase-Report.pdf

Potkewitz, H. (2008). Bronx Park victim of city budget cuts; Grant to transform vacant lot to green Space near tiffany Gardens Canceled. Crain's New York Business, (Oct), 20, 15.

Rottman, J., \& Lacity, M. (2008). A US client's learning from outsourcing IT work offshore. Information System Frontiers,10(2), 259-275.

Sabherwal, R. (1999). The role of trust in outsourced IS development projects. Communications of ACM, 42 (2), 80-86. Sen, F., \& Shiel, M. (2006). From business process outsourcing to knowledge process outsourcing: Some issues. Human Systems Management, 25(2), 145155.

Siegenthaler, K., \& Gonzalez, G. (1997). Youth sports as serious leisure: A critique. Journal of Sport \& Social Issues, 21(3), 298-314.
Silverman, B. (1999). Technological resources and the direction of corporate diversification: toward an integration of the resource-based view and transaction cost economics. Management Science, 45, 1109-1124.

Stake, R. (1995). The art of case study research. Thousand Oaks, CA: SAGE Publications.

Statista (2013). Statistics and facts on the business process outsourcing industry worldwide. Retrieved from http://www.statista.com/topics/225 $7 /$ business-process-outsourcingindustry-worldwide/

Sword, D. (2009). Grant cuts hurt plans for parks; Legislature: Two local groups werehoping for $\$ 10$ million this year. Sarasota Herald-Tribune, (Jan) 24, BS1.

Teng, J., Cheon, M., \& Grover, V. (1995). Decisions to outsource information systems functions: testing a strategytheoretic-discrepancy model. Decision Sciences, 26(1), 75-103.

Thomas, I. (2015). NHL presses to make hockey more affordable. Sports Business Journal, 18(17), 16.

Walker, M., Sartore, M., \& Taylor, R. (2009). Outsourced marketing: it's the communication that matters. Management Decision, 47(6), 895-918. Whipp, R., Hutton, H., Gove, R., \& Jackson, B. (2011). Outsourcing physical education primary schools: Evaluating the impact of externally provided programs on generalist teachers. Asia-Pacific Journal of Health, 
Sport and Physical Education, 2(2), 6777.

Willcocks, L., Lacity, M., \& Kern, T. (1999). Risk mitigation in IT outsourcing strategy revisited: longitudinal case research at LISA. Journal of Strategic Information Systems, 8(3), 285-314.

Williamson, O. (1985). The economic institutions of capitalism. New York: Free Press.

Williamson, O. (1975). Markets and bierarchies: Analysis and antitrust implications. New York: Free Press.

Woodside, A., \& Wilson, E. (2002).

Respondent inaccuracy: An examination of self-report and actual purchase behavior. Journal of Advertising Research, 42, 7-18.

Wullenweber, K., Beimborn, D., Weitzel, T., \& Konig, W. (2008). The impact of process standardization on business process outsourcing success. Information Systems Frontiers, 10(2), 210-224.

Yin, R. (1981). The case study as a serious research strategy. Knowledge: Creation, Diffusion, Utilization, (3)1, 97-114.

Zach, M., \& Singh, S. (2010). A knowledgebased view of outsourcing. International Journal of Strategic Change Management, 2(1), 32-53.

Zullo, R. (2013a). Future trends in outsourced marketing within Division I intercollegiate athletics: An initial round of Delphi study. Journal of Applied Sport Management: Research that Matters, 5(3), 24-54.
Zullo, R. (2013b). Restricted sponsorships and outsourced marketing in Division I intercollegiate athletics. Journal of Contemporary Athletics, 7(3), 1-18. 


\section{Tables}

Table 1

\section{City Profile}

\begin{tabular}{lccc} 
Cases & $\begin{array}{l}\text { Year 2014 Estimated } \\
\text { Population }\end{array}$ & $\begin{array}{c}\text { Population Percentage } \\
\text { Change (Year 2010 } \\
\text { Year 2014) }\end{array}$ & $\begin{array}{c}\text { Median Household Income } \\
\text { (Year 2009-2013) }\end{array}$ \\
\hline Case 1 & 17,527 & $-0.3 \%$ & \\
Case 2 & 34,604 & $+1.0 \%$ & $\$ 54,225$ \\
Case 3 & 26,523 & $-0.5 \%$ & $\$ 63,924$ \\
- & & & $\$ 53,586$ \\
\hline
\end{tabular}

Source: United States Census Bureau. 


\section{Table 2}

\section{City Profile}

\begin{tabular}{|c|c|c|c|}
\hline Cases & Outsourcing Risk & $\begin{array}{l}\text { Outsourcing Risk } \\
\text { Mitigation Plans }\end{array}$ & $\begin{array}{l}\text { Outsourcing Mitigation } \\
\text { Satisfaction }\end{array}$ \\
\hline Case 1 & Low & $\begin{array}{l}\text { Monitoring, } \\
\text { Communication, } \\
\text { Contract Details }\end{array}$ & High \\
\hline
\end{tabular}

Case 2

Extremely Low

Monitoring,

High

Communication

Case 3 Extremely Low

Monitoring,

High 
Table 3

Example of Case 1 YSP Outsourcing Revenue

\begin{tabular}{|c|c|c|c|c|}
\hline & $\begin{array}{l}\text { FY2014 } \\
\text { Revenue } \\
\text { (\% of } \\
\text { Revenue) }\end{array}$ & $\begin{array}{l}\text { FY2013 } \\
\text { Revenue } \\
\text { (\% of } \\
\text { Revenue) }\end{array}$ & $\begin{array}{l}\text { FY2012 } \\
\text { Revenue } \\
\text { (\% of } \\
\text { Revenue) }\end{array}$ & $\begin{array}{c}\text { FY2011 } \\
\text { Revenue } \\
\text { (\% of Revenue) }\end{array}$ \\
\hline $\begin{array}{l}\text { YSP } \\
\text { Outsourcing }\end{array}$ & $\begin{array}{l}\$ 14,270 \\
(1.07 \%)\end{array}$ & $\begin{array}{l}\$ 17,344 \\
(1.19 \%)\end{array}$ & $\begin{array}{l}\$ 17,160 \\
(1.19 \%)\end{array}$ & $\begin{array}{l}\$ 16,836 \\
(1.17 \%)\end{array}$ \\
\hline YSP In-House & $\begin{array}{l}\$ 33,985 \\
(2.54 \%)\end{array}$ & $\begin{array}{l}\$ 36,924 \\
(2.53 \%)\end{array}$ & $\begin{array}{l}\$ 26,082 \\
(1.81 \%)\end{array}$ & $\begin{array}{l}\$ 41,330 \\
(2.88 \%)\end{array}$ \\
\hline Total & $\begin{array}{l}\$ 50,369 \\
(3.61 \%)\end{array}$ & $\begin{array}{l}\$ 56,281 \\
(3.71 \%)\end{array}$ & $\begin{array}{l}\$ 45,254 \\
(3.00 \%)\end{array}$ & $\begin{array}{l}\$ 60,177 \\
(4.05 \%)\end{array}$ \\
\hline
\end{tabular}




\section{Figures}

Figure 1

Economic and Strategic Management View in Amateur Sport Outsourcing

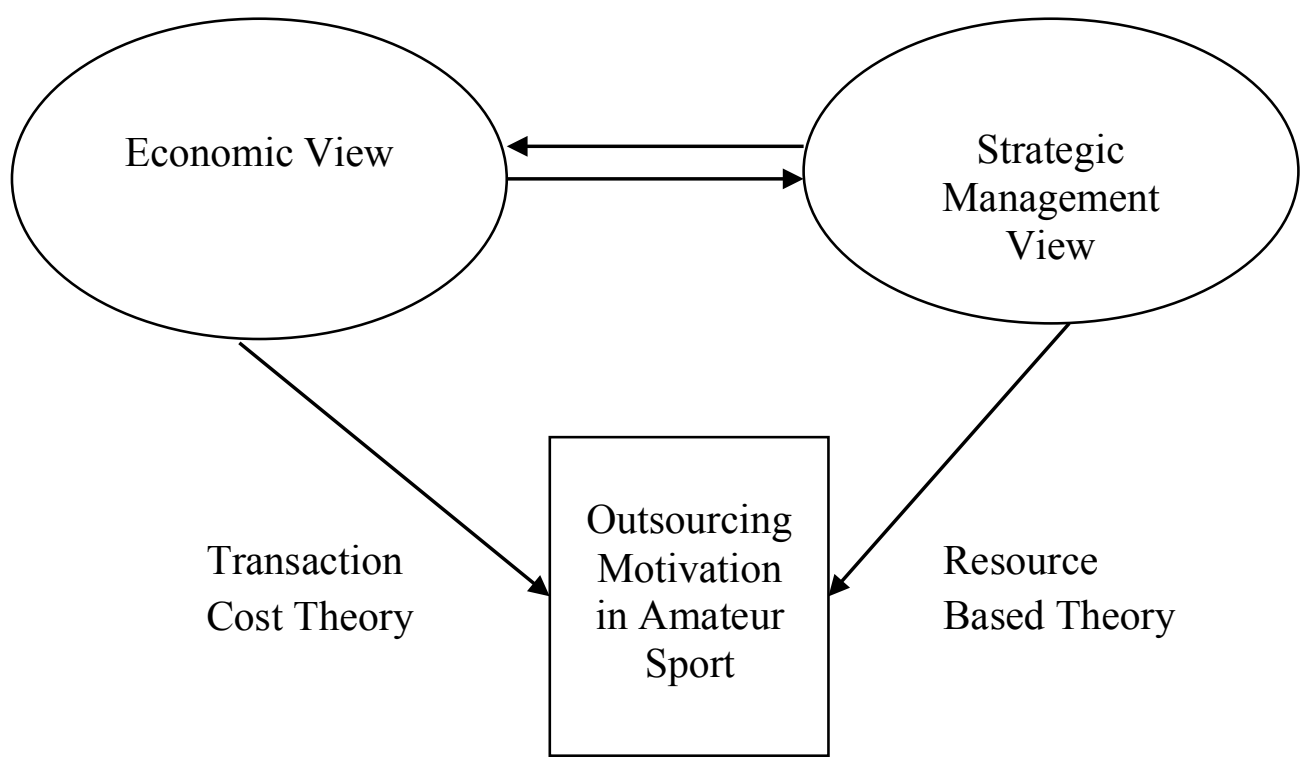

